\title{
A Probe into the Biphasic Nature of the Acetone Butanol Ethanol (ABE) Fermentation by Clostridium acetobutylicum ATCC 824
}

\author{
C. Vijayanand ${ }^{1}$, S. Kamaraj ${ }^{1}$, S. Sriramajayam ${ }^{1}$, S. Karthikeyan ${ }^{1}$, \\ A. Surendrakumar ${ }^{2}$ and D. Ramesh ${ }^{1}$ \\ ${ }^{1}$ Department of Bioenergy, Agricultural Engineering College and Research Institute, Tamil Nadu \\ Agricultural University, Coimbatore, TamilNadu, India \\ ${ }^{2}$ Agricultural Machinery Research Centre, Agricultural Engineering College and Research \\ Institute, Tamil Nadu Agricultural University, Coimbatore, Tamil Nadu, India \\ *Corresponding author
}

A B S T R A C T

\begin{tabular}{|l|}
\hline Ke y w or d s \\
Paddy straw, \\
Pretreatment, \\
Acid Hydrolysis, \\
Hydrolysate, \\
Fermentation, \\
Butanol. \\
\hline Article Info \\
\hline Accepted: \\
20 March 2017 \\
Available Online: \\
10 April 2017 \\
\hline
\end{tabular}

Butanol is a virtually promising bio fuel of our future imputing to its higher blending ratios in petrol and diesel without any retrofitting in IC engines. Biobutanol was produced from Acetone Butanol and Ethanol (ABE) fermentation of $5 \%$ ortho phosphoric acid pretreated paddy straw biomass using Clostridium acetobutylicum ATCC 824 strain. ABE fermentation was a zymolysis process of Clostridium bacteria, the anaerobic breakdown of sugars into alcohols in which the solvents formed were a result of two different phases of acidogenesis and solventogenesis. The optimal $\mathrm{pH}$ for maximal conversion of sugars into alcoholic compounds was 5.2-5.8.

\section{Introduction}

The global awakening for the conversion of second generation lignocellulosic biomass to alcoholic fuel sources has led to a fruitful insight in discovering inexpensive resources for fermentation and recent advances in biotechnology and bioprocessing has provided successful production of biofuels using fermentation (Kumar et al., 2012).

Clostridium bacteria are isolated from soil, corn meal, putrefying matter, potatoes and also from the root modules of $\mathrm{N}_{2}$ fixing phytoplankton (Syed, 1994). Typically
Clostridia exhibit biphasic (acidogenic and solventogenic) fermentation behaviour. During the acidogenic phase observed during the exponential phase, cells produce acetate and butyrate with medium $\mathrm{pH}$ around 5.7 and once it further reach around $\sim 4.8$, the cells cease acid production. Subsequently, the acids are reassimilated and solvents are produced.

Butanol $\left(\mathrm{C}_{4} \mathrm{H}_{9} \mathrm{OH}\right)$, i.e. butyl alcohol or 1butanol or n-butanol, is a primary alcohol made up of four carbon structure with a molecular weight of 74.12. Butanol is a 
colourless liquid with a distinctly sweet odour, utilized as solvent in industries (Green, 2011). Around 4.5 to 5.5 million tonnes of butanol are produced per annum (Ramey and Yang, 2004). This accounts for $9 \times 10^{9}$ dollar market with an annual market expansion of $3 \%$ per year (Cascone, 2008).

Acetone Butanol Ethanol (ABE) fermentation is the utilization of direct sugars from cane molasses, corn etc. or sugars released by hydrolysis of agricultural biomass and its utilization as substrate, the solvent fermentation yields acetone, butanol and ethanol in the ratio of $3: 6: 1$.

In the present study, the $\mathrm{ABE}$ fermentation was carried with dilute $\mathrm{H}_{3} \mathrm{PO}_{4}$ pre-treated paddy straw hydrolysate as the carbon source with an efficient Clostridium acetobutylicum strain ATCC 824.

\section{Materials and Methods}

\section{Dilute acid pre-treatment of paddy straw}

The paddy straw substrate for fermentation was prepared by milling and grinding dried paddy straw to powder form of $600 \mu \mathrm{m}$ particle size. To $100 \mathrm{~g}$ of the paddy straw sample $5 \%$ of orthophosphoric acid diluted and acidified in a double distilled water of $1000 \mathrm{ml}$ was prepared. The biomass sample was added to this acidified $5 \% \quad \mathrm{H}_{3} \mathrm{PO}_{4}$ distilled water and acid hydrolysis was carried out at $121^{\circ} \mathrm{C}$ temperature for a time period of 1h. From this acid hydrolysis sample, the biomass and acidified rice straw hydrolysate (liquid substrate) were separated through filtration. The sugars in the substrate were determined by DNS method.

\section{Clostridium acetobutylicum ATCC 824 inoculum}

The media for cultivation of clostridium bacteria was prepared with casein enzymatic hydrolysate $10 \mathrm{~g}$, beef extract $10 \mathrm{~g}$, yeast extract $3 \mathrm{~g}$, dextrose $5 \mathrm{~g}$, sodium chloride $5 \mathrm{~g}$, sodium acetate $3 \mathrm{~g}$, soluble starch $1 \mathrm{~g}$, Lcysteine hydrochloride $0.5 \mathrm{~g}$ and these constituents were suspend in $1000 \mathrm{ml}$ of double distilled sterile water. The composition was heated to boiling and then to dissolve the medium completely. Then it was sterilized by autoclaving at 15 psi pressure at a temperature of $121^{\circ} \mathrm{C}$ for 15 minutes, the final $\mathrm{pH}$ at $25^{\circ} \mathrm{C}$ was $6.8 \pm 0.2$. Clostridium acetobutylicum ATCC 824 culture utilized for inoculation in the fermenter, was grown in moulded flint glass vials.

\section{Gas chromatography and mass spectroscopy detector}

The fermented liquor was analysed in Agilent technologies GC (Gas Chromatograph) 7890B coupled with MSD 5977 (Mass Spectroscopy Detector). The Agilent 7693A automatic liquid sampler (ALS) was used to inject the sample into the analyser oven from the sampler for pyrolysis of the sample.

\section{Results and Discussion}

The carbon source for $\mathrm{ABE}$ fermentation was paddy straw hydrolysate derived from acid hydrolysis using dilute orthophosphoric acid. The fermentation was carried out using Clostridium acetobutylicum ATCC 824 strain, when the bacteria was observed to have passed the lag phase of growth and already in the log phase at a 40 to $48 \mathrm{~h}$, the inoculum was transferred to the fermentation vessel holding the substrate and the $\mathrm{ABE}$ fermentation was initiated. The volume of inoculum transferred was $10 \%$ the total volume of the substrate.

The fermentation was carried out in a pilot scale fermenter, the $\mathrm{pH}$ of the fermentation liquor was monitored at regular intervals, and the anaerobic atmosphere was maintained by flushing the reactor with nitrogen, the sugar 
level was monitored at regular intervals to cognize the microbial growth and bioconversion of sugars to solvents. $\mathrm{ABE}$ fermentation is the anaerobic breakdown of sugars into alcohols in which the solvents formed were an outcome of two phases of fermentation, acidogenesis and solventogenesis respectively (Fig. 1). The energy flux in the form of carbon source for the fermentation involved the conversion of hexose sugars to pyruvate; the pathway involved was Embden-Meyerhof pathway. In this pathway two moles of pyruvate was formed from each mole of hexose sugar, two moles of ATP (adenosine triphosphate) was formed from one mole of hexose and NADH (nicotinamide adenine dinucleotide) was reduced by two moles.

Castano (2003) reported the utilization of pentose sugars in the fermentation had involved pentose phosphate pathways, wherein pentose-5-phosphates were formed by the bioconversion of pentose. The conversion proceeded into the pathway of glycolysis or glycolytic pathway. During this pathway, five moles of NADH were yielded from three moles of pentose sugars. The further degradation or breakdown of gluconates (acid sugars) by modified EntnerDoudroff pathway. The transfer of monosaccharides and disaccharides uptake by the bacteria occured through PTS (Phosphotransferase) system however the transport of galactose into the bacterial cell was not aided by the PTS system. However, the involvement of the pathways and galactose transport was not studied in the current.

The acidogenic phase is the phase in which, acetate $\left(\mathrm{CH}_{3} \mathrm{CO}_{2}\right)$, butyrate $\left(\mathrm{C}_{4} \mathrm{H}_{8} \mathrm{O}_{2}\right), \mathrm{H}_{2}$ and $\mathrm{CO}_{2}$ are evolved, this was in exponential growth phase, which further resulting in a decrease in $\mathrm{pH}$ of the fermentation liquor. In this phase acetates and butyrates were produced from actyl-CoA $\left(\mathrm{C}_{23} \mathrm{H}_{38} \mathrm{~N}_{7} \mathrm{O}_{17} \mathrm{P}_{3} \mathrm{~S}\right)$ and butyryl-CoA $\left(\mathrm{C}_{25} \mathrm{H}_{42} \mathrm{~N}_{7} \mathrm{O}_{17} \mathrm{P}_{3} \mathrm{~S}\right)$, proceeded by a two step production of acylphosphates $\left(\mathrm{CHO}_{5} \mathrm{P}\right)$ and ATP. The acyl phosphates were further converted to acetate and butyrate (Fig. 2 and 3) by the action of the enzymes acetates and kinase such similar conversions were addressed along with the organism producing lactase from pyruvate by C. acetobutylicum by Lee et al., 2008.

During the acidogenesis phase excess amounts of reducing equivalents were formed of which only a certain portion was formed as a result of glycolysis were consumed for fermentation. These excess amounts of reducing equivalents are transferred to hydrogenase, which resulted in the evolving of hydrogen as a product of transferring electrons to protons, which is the final acceptor of electron. The aldehydes and alcoholic dehydrogenases took in one mole of $\mathrm{C}_{21} \mathrm{H}_{29} \mathrm{~N}_{7} \mathrm{O}_{17} \mathrm{P}_{3}$, NADPH (nicotinamide adenine dinucleotide) for each mole of the hydrolysate/substrate for conversion into fermentation products. The acetyl-CoA $\left(\mathrm{C}_{23} \mathrm{H}_{38} \mathrm{~N}_{7} \mathrm{O}_{17} \mathrm{P}_{3} \mathrm{~S}\right)$ and $\mathrm{NADH}$ acted as the sensors for $\mathrm{H}_{2}$ and ATP generation along with the primal role of electron flow regulation into the cell. When the Clostridium culture reaches its stationary phase of growth, a shift in its metabolism occurred in order to form solvents, this phase was the solventogenic phase; the solvents formed were acetone, butanol and ethanol. The solvents production in this phase of solventogenesis is the result of acid assimilation with simultaneous intake of carbohydrates. During the growth phase of Clostridium acetobutylicum the solvent production was observed to be established, the key end fermentation products being acetic acid, butyric acid, $\mathrm{CO}_{2}$ and $\mathrm{H}_{2}$. Further this solvent production marked a switch in the flow of energy as carbon from acid producing pathways to solvent producing pathways. 
Table.1 A.B.E Fermentation data

\begin{tabular}{lll}
\hline Time, h & pH & Sugars, ppm \\
\hline 24 & 7.60 & 12.84 \\
48 & 6.24 & 10.27 \\
72 & 5.42 & 5.50 \\
96 & 5.80 & 5.07 \\
\hline
\end{tabular}

Table.2 Results of GC MSD analysis

\begin{tabular}{llc}
\hline Name of compound & $\begin{array}{l}\text { Retention } \\
\text { time, min }\end{array}$ & Area \% \\
\hline Ethanol & 1.86 & 5.77 \\
Acetic acid & 2.03 & 10.04 \\
Butanol & 3.11 & 21.29 \\
Furfural & 4.80 & 0.68 \\
\hline
\end{tabular}

Fig.1 Metabolic pathway of Clostridium acetobutylicum

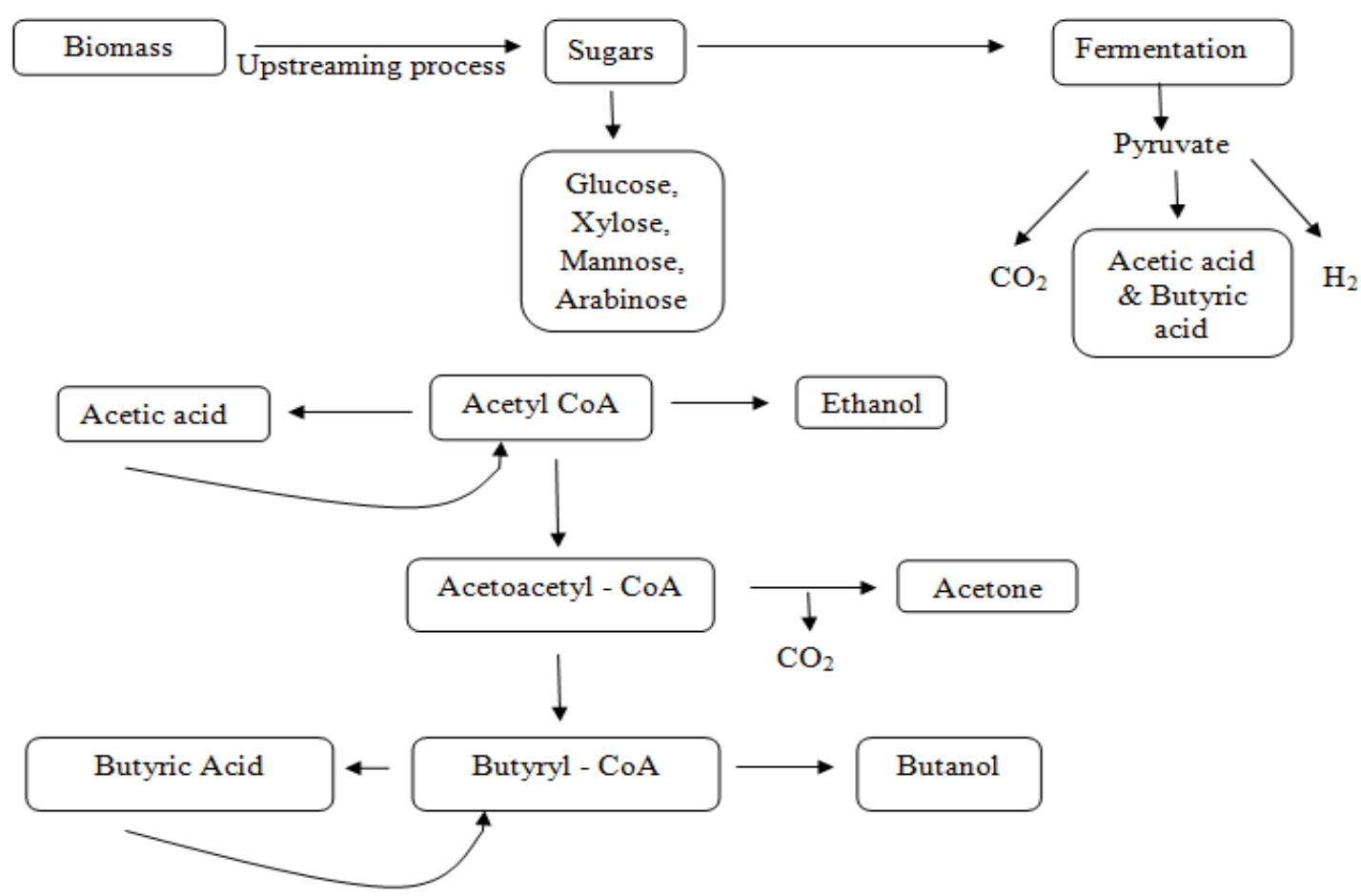


Fig.2 Acetate formation from pyruvate

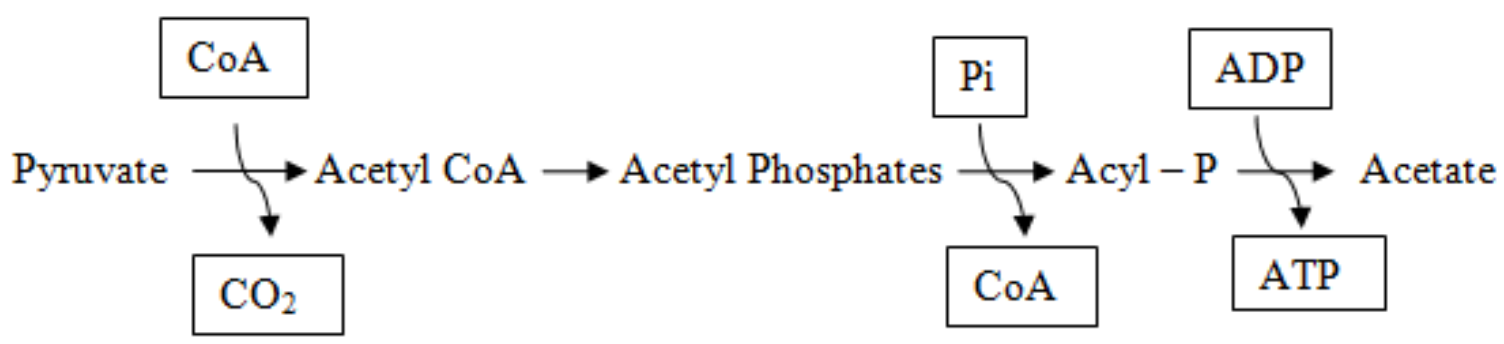

Fig.3 Butyrate formation and butanol synthesis
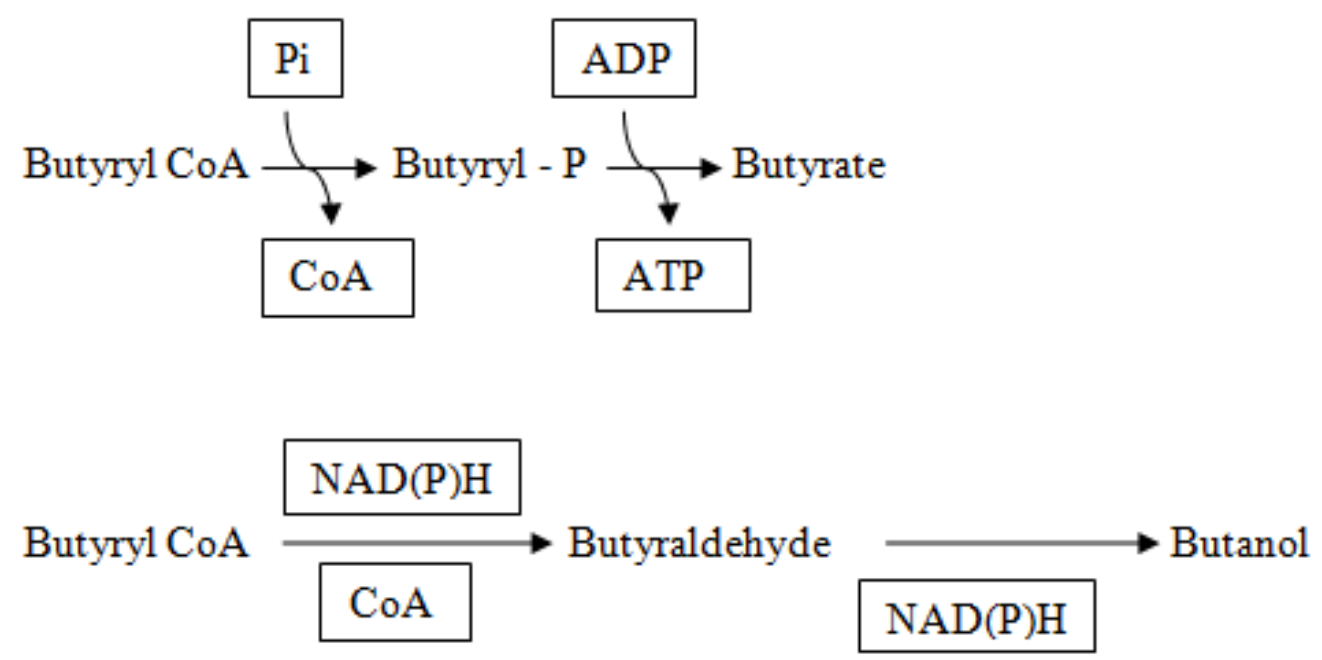

Fig.4 Variation in $\mathrm{pH}$ and sugar level during different time intervals of fermentation

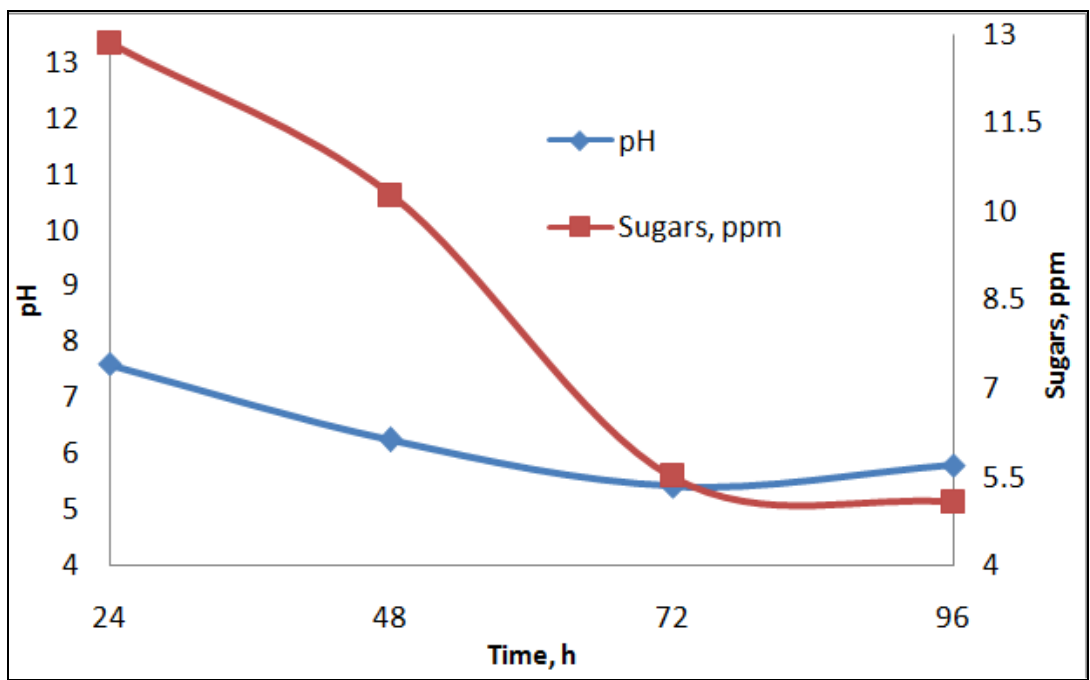


Fig.5 Graphical representation of gas chromatography and mass spectroscopy detection (GC-MSD) of A.B.E fermented liquor

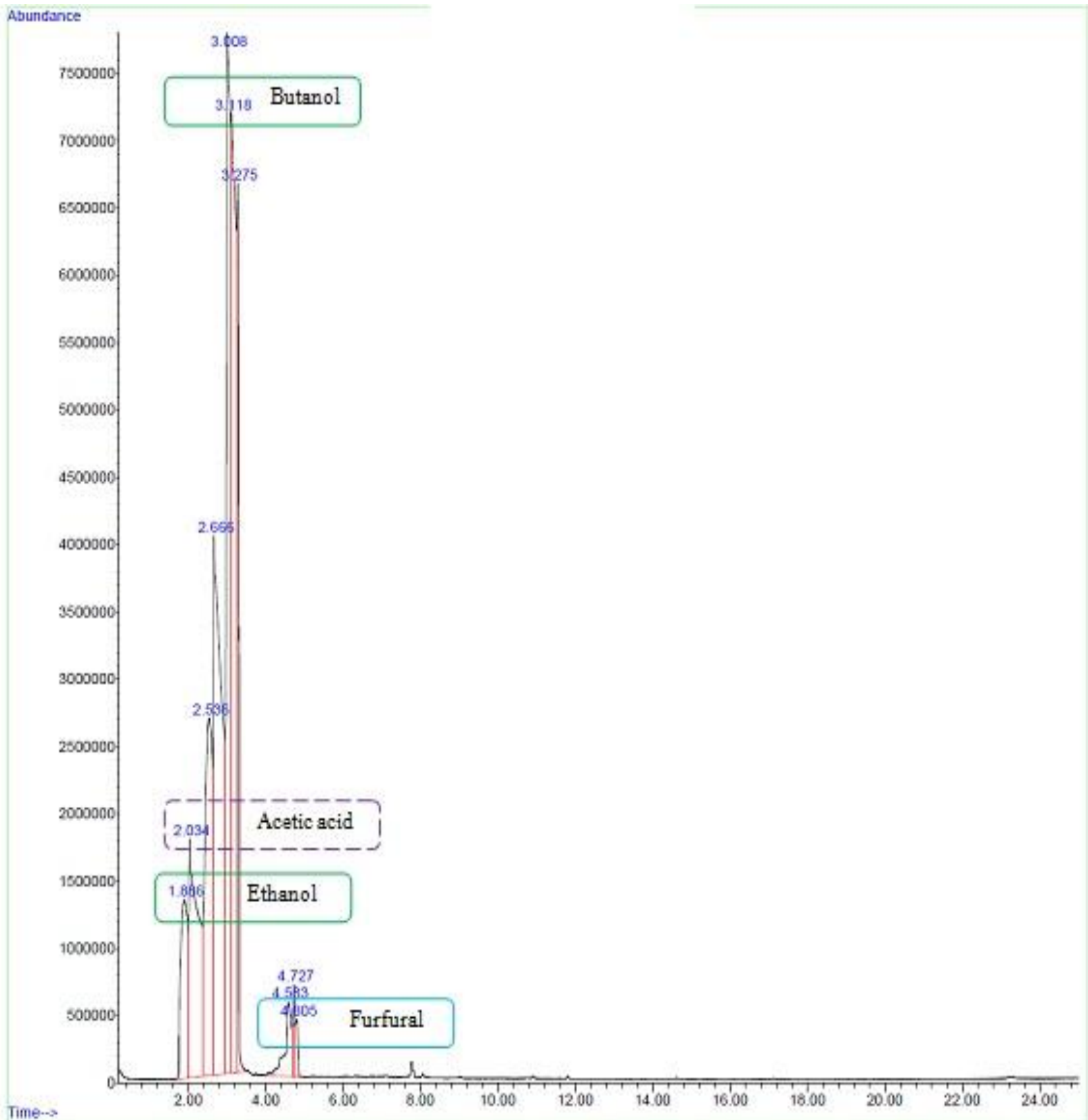

During this solvent producing phase acetyl$\mathrm{CoA}\left(\mathrm{C}_{23} \mathrm{H}_{38} \mathrm{~N}_{7} \mathrm{O}_{17} \mathrm{P}_{3} \mathrm{~S}\right)$ and butyryl-CoA $\left(\mathrm{C}_{25} \mathrm{H}_{42} \mathrm{~N}_{7} \mathrm{O}_{17} \mathrm{P}_{3} \mathrm{~S}\right)$ functional groups were the key intermediates through which ethanol and butanol from acylCoA groups. Before the synthesis of ethanol and butanol the acetyl-CoA was reduced to acetaldehyde $\left(\mathrm{CH}_{3} \mathrm{CHO}\right)$ by acetaldehyde dehydrogenase
$\left(\mathrm{CH}_{3} \mathrm{CHO}\right.$ DHase) and butyryl-CoA was reduced to butyraldehyde $\left(\mathrm{C}_{4} \mathrm{H}_{8} \mathrm{O}\right)$ by the action of butyraldehyde dehydrogenase $\left(\mathrm{C}_{4} \mathrm{H}_{8} \mathrm{O}\right.$ DHase $)$. The principle enzymes involved in butanol production were discovered to be dependent on NADH and NADPH. Since the ABE fermentation was observed to be in a biphasic nature, in the 
acidogenesis phase, of butyric acid fermentation the $\mathrm{H}_{2}$ yielded was balanced by the quantity of acetate produced. In the acidogenesis phase for each mole of the glucose consumed, $3.25 \mathrm{~mol}$ of ATP was produced whereas in solventogenesis phase proceeding it the yield in $\mathrm{H}_{2}$ was noticed to be decreased with a surge in $\mathrm{CO}_{2}$ and solvent yields. The total quantity of acids were much lower in solventogenesis phase, this could be attributed to the acculturation of acids in this phase. Bahl et al., (1982) and Monot et al., (1984) have mentioned that the concentration of acetic and butyric acids conglomeration affects the solventogenic phase and ultimately solvents production.

From figure 4 the $\mathrm{pH}$ and sugar concentration of the fermentation liquor can be depicted. The figure illustrates a gradual decrease in the sugar concentration of the fermentation liquor which is attributed to the fact that there was an increase in the growth in the bacterial population and also the acidic $\mathrm{pH}$ has rendered salubrious environment for solvent production (Table 1). The $\mathrm{H}^{+}$ion concentration, $\mathrm{pH}$ influenced the $\mathrm{ABE}$ fermentation, when the concentration of acetate and butyrate acids increased, the bacteria changed over to a new order sequence of producing solvents, this affirmed that the acidic $\mathrm{pH}$ sparked off the bacterial culture to produce the alcoholic groups (solvents), hence intervening and detoxifying the acids synthesized. The sugars concentration persisted to decline when the $\mathrm{pH}$ was acidic. From this was inferred that the clostridium acetobutylicum cultures were attributed to the nature of upholding a constant $\mathrm{pH}$ across the membrane, with $\Delta \mathrm{pH}$, a vital necessity of the organism for metabolism and growth. Zhao et al., (2005) had also experienced and reported about a similar relationship between $\mathrm{pH}$ and $\Delta \mathrm{pH}$ with the metabolism of Clostridium acetobutylicum.
The analysis of A.B.E fermented liquor was carried out in a gas chromatograph with a mass spectroscopy detector. The retention time of $<0.008 \mathrm{~min}$ was fixed with oven temperature range of 50 to $300^{\circ} \mathrm{C}$ at $120 \mathrm{~V}$, $15 \mathrm{~A}$ through a single channel at maximum run time of 60 minutes. The carrier gas were helium and nitrogen with flow rates of < $\pm 0.20 \mathrm{~mL} / \mathrm{min}$ per ${ }^{\circ} \mathrm{C}$ and $< \pm 0.05 \mathrm{~mL} / \mathrm{min}$ per ${ }^{\circ} \mathrm{C}$. The results of the analysis are shown in figure 5, in which the presence of compounds like butanol, ethanol, acetic acid, furfural was observed. The results affirmed the conversion of the sugars to acids and solvents, ethanol $\left(\mathrm{C}_{2} \mathrm{H}_{6} \mathrm{O}\right)$ was observed for the retention time of 1.86 minutes with a compound purity of $33 \%$ (Table 2).

Butanol $\left(\mathrm{C}_{4} \mathrm{H}_{9} \mathrm{OH}\right)$ was observed to have occupied the majority of area with $21.29 \%$ for the retention time of 3.11 minutes; its purity was $80 \%$. There were also fermentation inhibiting compounds like furfural $\left(\mathrm{C}_{5} \mathrm{H}_{4} \mathrm{O}_{2}\right)$ present in the fermented liquor along with the solvents, the presence of acetic acid $\left(\mathrm{CH}_{3} \mathrm{COOH}\right)$ was also noted which indicated that total conversion of all the acidic compounds produced during the acidogenesis to solvents did not take place in the solventogenic phase.

The percentage of furfural was relatively low by which it was inferred that its presence has not cause any hindrance during the fermentation phases.

In conclusion, the $\mathrm{ABE}$ fermentation involved two different phases, an acidogenic phase wherein a rise in bacterial population and growth, tending to the formation of acetic acid and butyric acid along with fermentation gases $\left(\mathrm{CO}_{2}\right.$ and $\left.\mathrm{H}_{2}\right)$ from the pyruvate obtained from the sugars by glycolysis. At the end of the exponential growth phase, bacterial metabolism altered 
and the production of acetone, butanol and ethanol from the acids was noticed. In the solventogenic phase product concentrations remained low and the presence of butanol in fermented liquor inhibited the growth and metabolism of bacterial culture.

\section{Acknowledgements}

The author would like to acknowledge University Grants Commission (UGC) and Ministry of Social Justice and Empowerment.

\section{References}

Bahl, H., Andersch, W., and Gottschalk, G. 1982. Continuous Production of Acetone and Butanol by Clostridium acetobutylicum in a Two-Stage Phosphate Limited Chemostat. European J. Appl. Microbiol. Biotechnol., 15: 201-205.

Cascone, R. 2008. Biobutanol a replacement for bioethanol? Chemical Engineering Progress, S4-S9.

Castano, D.M. 2003. Anaerobic, solventproducing bacteria: Molecular characterisation, polysaccharolytic activity and agro industrial waste degradation. Thesis submitted to Department of Microbiology of the Technical University of Munich.

Green, E.M. 2011. Fermentative production of butanol the industrial perspective. Curr. Opinion in Biotechnol., 22: 1-7.
Kumar, M., Goyal, Y., Sarkar, A., and Gayen, K. 2012. Comparative economic assessment of $\mathrm{ABE}$ fermentation based on cellulosic and rd non-cellulosic feed stocks. Appl. Energy, [http://dx.doi.org/10.1016/j.apenergy.20 11.12.079]

Lee, S.Y., Park, J.H., Jang, S.H., Nielsen, L.K., Kim, J. and Jun, K.S. 2008. Review: Fermentative Butanol Production by Clostridia. Biotechnol. Bioengi., 101(2): 209-228.

Monot, F., Engasser, J.M. and Petitdemange, H. 1984. Influence of $\mathrm{pH}$ and undissociated butyric acid on the production of acetone and butanol in batch cultures of Clostridium acetobutylicum. Appl. Microbiol. Biotechnol., 19: 422-426.

Ramey, D. and Yang, S.T. 2004. Production of Butyric Acid and Butanol from Biomass. Final Report for: US Department of Energy (DOE).

Syed, Q. 1994. Biochemical studies on anaerobic fermentation of molasses $y$ Clostridium acetobutylicum. Thesis submitted to Institute of Chemistry, Pakistan.

Zhao, Y., Tomas, C.A., F. Rudolph, B., Papoutsakis, E.T. and Bennett, G.N. 2005. Intracellular Butyryl Phosphate and Acetyl Phosphate Concentrations in Clostridium acetobutylicum and Their Implications for Solvent Formation. Appl. Environ. Microbiol., 71(1): 530535.

\section{How to cite this article:}

Vijayanand, C., S. Kamaraj, S. Sriramajayam, S. Karthikeyan, A. Surendrakumar and Ramesh, D. 2017. A Probe into the Biphasic Nature of the Acetonebutanolethanol (ABE) Fermentation by Clostridium acetobutylicum ATCC 824. Int.J.Curr.Microbiol.App.Sci. 6(4): 2179-2186. doi: https://doi.org/10.20546/ijcmas.2017.604.255 